\title{
THE EFFECT OF PH AND HARDNESS METAL IONS ON THE COMPETITIVE INTERACTION BETWEEN TRACE METAL IONS AND INORGANIC AND ORGANIC COMPLEXING AGENTS FOUND IN NATURAL WATERS
}

\author{
Timothy A. O'SheA*† and Khalil H. Mancy \\ Department of Environmental and Industrial Health, School of Public Health, The University of \\ Michigan, Ann Arbor, MI 48104, U.S.A.
}

(Received 3 March 1977; accepted for publication 6 January 1978)

\begin{abstract}
The effect of $\mathrm{pH}$ and hardness metal ions on the interactions between trace metals and both inorganic and organic complexing agents has been studied under conditions simulating natural aquatic conditions, by employing anodic stripping voltammetric titration techniques. The complexation of $\mathrm{Bi}(\mathrm{III}), \mathrm{Cd}(\mathrm{II}), \mathrm{Cu}(\mathrm{II}), \mathrm{Pb}(\mathrm{II})$, and $\mathrm{Tl}(\mathrm{I})$ with the hydroxo- and carbonato-ligands found in a carbonate medium has been observed to generally increase with increasing $\mathrm{pH}$. Both labile and nonlabile interactions have been observed. Nonlabile interactions are predominant at low $\mathrm{pH}$ and labile interactions generally increase with increasing $\mathrm{pH}$. Neither calcium nor magnesium affects these interactions. The complexation of humic acids with trace metals in a carbonate medium was found to be more intense than metal ion-inorganic complexation. Both labile and nonlabile complexation was found; however, no generalizations can be made concerning the type and extent of complexation because of the individual nature of the interactions of each trace metal. Calcium was found to be more effective than magnesium in inhibiting trace meta-organic complexation. The effect of calcium is to inhibit labile complexation and is most pronounced with the cadmium-humic acid system.
\end{abstract}

\section{INTRODUCTION}

The aquatic chemistry of trace metals in the natural environment is dependent on the distribution dynamics of these metals and on the types of interactions between the metals and their aquatic habitat. The physicochemical characteristics of the aqueous phase (Mancy, 1971), the interactions with the inorganic and organic components of suspended and sedimentary solid material (Guy, Chakrabarti \& Schramm, 1975; Guy \& Chakrabarti, 1976), and the availability of both inorganic and organic complexing agents (Gardiner, 1974; Chau, Gachter \& Lum-Shue-Chan, 1974; Chau \& Lum-Shue-Chan, 1974) can greatly influence the distribution of trace metals and their subsequent effect on the aquatic biota.

Knowledge concerning the complexation and adsorption of trace metals with components of their aqueous environment is somewhat obscure because of the uncertainty associated with the role of hardness metal ions; specifically, calcium and magnesium, on these interactions. The presence of these metal ions in the natural environment at concentrations a thousand-fold or more greater than that of trace metals introduces the possibility that the coordination tendency of available ligands might be satisfied by the

- Present address: Department of Chemistry, Texas Wesleyan College, P.O. Box 3277, Fort Worth, Texas 76105, U.S.A.

† To whom correspondence should be addressed. hardness metal ions even though they generally form weaker complexes than the trace metals (Stumm \& Morgan, 1970). If this is the case, the hardness metal ions would successfully compete with trace metals for available binding sites. The net result would be an inhibition of trace metal complexation and/or adsorption and a higher percentage of "free", hydrated metal in the aqueous phase. Such competitive interactions would certainly affect the distribution and dynamics of the trace metals and might significantly alter their availability to aquatic organisms.

Studies of the effects of hardness metal ions on the complexation or adsorption of trace metals in natural waters are extremely limited. Maljkovic \& Branica (1971) used square-wave polarography to study the effect of calcium on the complexation of cadmium with EDTA in both seawater and $\mathrm{NaCl}$ solutions. They observed decreased complexation of cadmium in the presence of calcium and suggested that calcium preferentially complexed with EDTA. and thus removed potential binding sites for cadmium. Calculations by Gardiner (1976) indicated that the complexation of cadmium by EDTA is significantly reduced as the calcium to EDTA concentration ratio is increased. Similar effects were predicted for other trace metal ions. Lasheen (1974) found that calcium. in the presence of organic matter, reduced the extent of cadmium uptake by sediments. The opposite effect was found with lead and copper. Guy \& Chakrabarti (1976) studied the release of copper from particulate 
suspensions of clay and humic acid upon addition of calcium to equilibrated solutions. The amount of copper released was observed to increase with increasing concentrations of calcium. The mechanism for this release was determined to be ion exchange.

The present study describes the investigation of the competitive interactions between hardness metal ions and five trace metal ions for both inorganic and organic complexing ligands as a function of $\mathrm{pH}$ and under conditions similar to those encountered in many natural water systems. The study was conducted by observing changes in the anodic stripping voltammetric characteristics of the trace metals during metal-ligand titrations in a carbonate medium buffered at the desired $\mathrm{pH}$ by deaerating with the appropriate $\mathrm{CO}_{2}-\mathrm{N}_{2}$ gas mixture. The basis and technique for such analyses have been previously reported by Mancy (1973) and O'Shea \& Mancy (1976). The five trace metal ions investigated were bismuth(III). cadmium(II), copper(II), lead(II), and thatlium(I).

\section{EXPERIMENTAL}

The instrumentation, cell and electrode system, supporting electrolyte, deaeration and buffer system, and general procedure have been described by O'Shea \& Mancy (1976). Plating potentials were $-1.000 \mathrm{~V}$ for copper and bismuth and $-1.400 \mathrm{~V}$ for cadmium, lead, and thallium. All potentials refer to the saturated mercury-mercurous sulfate $\left(\mathrm{Hg} / \mathrm{Hg}_{2} \mathrm{SO}_{4}\right)$ electrode as reference. A $10 \mathrm{~min}$ plating time and a potential sweep rate of $42.9 \mathrm{mV} \mathrm{s}^{-1}$ were used throughout the study. A $10 \mathrm{~min}$ equilibration time was employed in those situations where additions were made to solutions.

Except for the humic acid, all chemicals were reagent grade. Calcium and magnesium were used as their nitrate salts. Double-distilled water was used throughout the experiments. A $1.0 \mathrm{mg} \mathrm{ml}^{-1}$ humic acid solution was prepared by dissolving $50 \mathrm{mg}$ commercial grade humic acid ( $\mathrm{K} \& \mathrm{~K}$ Laboratories. Plainview, N.Y.) in a minimum amount of $0.1 \mathrm{M} \mathrm{KOH}$ and diluting to $50 \mathrm{ml}$ with doubledistilled water.

\section{RESULTS AND DISCUSSION}

\section{Interactions with inorganic ligands}

The coordination chemistry occurring within a natural aquatic system may be viewed as the competitive interactions of three types of cationic species; namely, hydrogen ion, hardness metal ions, and trace metal ions, for the ligands present in the aqueous system. In an unpolluted fresh water system free of organic matter, the principal ligands will generally be hydroxide and the carbonate species; furthermore, the carbonate system will be the prevalent buffer regulating the $\mathrm{pH}$ of the system. In order to investigate the competitive interactions for these inorganic ligands under conditions somewhat similar to those encountered in the natural environment, a supporting electrolyte of $1.0 \times 10^{-3} \mathrm{M} \mathrm{Na}_{2} \mathrm{CO}_{3}$ and $9.0 \times 10^{-3} \mathrm{M}$ $\mathrm{K}_{2} \mathrm{SO}_{4}$ was employed. This supporting electrolyte permits control of the $\mathrm{pH}$ and, at the same time, maintains a relatively high ionic strength without the
Table I. The effect of $\mathrm{pH}$ and calcium on the anodic stripping voltammetric characteristics of $5.0 \times 10^{-8} \mathrm{M}$ trace metal in a carbonate medium

\begin{tabular}{lccccc}
\hline & & \multicolumn{2}{c}{ Calcium } & absent & \multicolumn{2}{c}{ Calcium present } \\
Metal & pH & $(\mu \mathrm{A})$ & $\left(\begin{array}{c}i_{\mathrm{p}} \\
(\mathrm{V})\end{array}\right.$ & $\begin{array}{c}i_{\mathrm{p}} \\
(\mu \mathrm{A})\end{array}$ & $\begin{array}{c}E_{\mathrm{f}} \\
(\mathrm{V})\end{array}$ \\
\hline $\mathrm{Bi}$ & 6.1 & 22.2 & -0.511 & 21.2 & -0.502 \\
& 7.1 & 17.0 & -0.515 & 15.6 & -0.513 \\
& 8.0 & 11.9 & -0.549 & 11.0 & -0.544 \\
$\mathrm{Cd}$ & 6.1 & 27.0 & -1.027 & 26.2 & -1.031 \\
& 7.1 & 22.4 & -1.035 & 23.6 & -1.036 \\
& 8.1 & 19.0 & -1.040 & 21.0 & -1.040 \\
$\mathrm{Cu}$ & 6.2 & 16.9 & -0.420 & 18.1 & -0.425 \\
& 7.1 & 10.2 & -0.437 & 9.4 & -0.438 \\
& 8.1 & 6.0 & -0.468 & 5.6 & -0.478 \\
$\mathrm{~Pb}$ & 6.2 & 23.7 & -0.837 & 22.1 & -0.838 \\
& 7.1 & 16.2 & -0.842 & 16.9 & -0.844 \\
& 8.0 & 12.8 & -0.872 & 13.0 & -0.879 \\
$\mathrm{Tl}$ & 6.2 & 10.5 & -1.006 & 10.0 & -1.006 \\
& 7.1 & 9.2 & -1.014 & 9.8 & -1.015 \\
& 8.1 & 8.9 & -1.018 & 9.2 & -1.020 \\
\hline
\end{tabular}

need to introduce ionic substances which might be foreign to the natural aqueous environment.

Table I summarizes the results of the analysis of $5.0 \times 10^{-8} \mathrm{M}$ solutions of each of the five trace metals in this supporting electrolyte at $\mathrm{pH} \mathrm{6,7,} \mathrm{and}$ 8. The results obtained in the absence of calcium represent the competition between hydrogen ion and the trace metal ions for the hydroxo- and carbonatoligands present in the solutions. Each trace metal shows a tendency toward decreasing $i_{\mathrm{p}}$ with increasing $\mathrm{pH}$. Applying the diagnostic criteria developed by O'Shea \& Mancy (1976), this decreasing sensitivity is the result of an interaction between the trace metals and the available inorganic ligands to produce a complex which dissociates so slowly that interaction with the working electrode is inhibited; i.e. an interaction which produces nonlabile complexes. Since the concentations of the hydroxo- and carbonato-ligands is increasing with increasing $\mathrm{pH}$, the continuously decreasing $i_{\mathrm{p}}$ with increasing $\mathbf{p H}$ indicates that the extent of nonlabile trace metal complexation increases with increasing $\mathrm{pH}$. Viewed in another sense, as the $\mathrm{pH}$ is lowered the hydrogen ion is able to compete more favorably with the trace metals. As a result, less nonlabile trace metal complexation occurs and $i_{p}$ increases.

A cathodic shift in $E_{p}$ is a qualitative indication of complexation, either labile or nonlabile. Table 1 shows that the $E_{\mathrm{p}}$ values in the absence of calcium become increasingly more cathodic with increasing pH. The nonlabile complexation indicated by the $i_{\mathrm{p}}$ data is a definite source of these cathodic shifts; however, the contribution of labile complexation whose existence would not be indicated by $i_{\mathrm{p}}$ data is also a possibility.

Table 2, which represents the changes in $i_{\mathrm{p}}$ and $E_{\mathrm{p}}$ for the data in the absence of calcium presented 
Table 2. The effect of $\mathrm{pH}$ on $i_{\mathrm{p}}$ and $E_{\mathrm{p}}$ for $5.0 \times 10^{-8} \mathrm{M}$ trace metal in the absence of calcium

\begin{tabular}{lccc}
\hline Metal & $\begin{array}{c}\mathrm{pH} \\
\text { Interval }\end{array}$ & $\begin{array}{c}\Delta i_{\mathrm{p}} \\
(\%)\end{array}$ & $\begin{array}{c}\Delta E_{\mathrm{p}} \\
(\mathbf{m V})\end{array}$ \\
\hline $\mathrm{Bi}$ & $6-7$ & 23.4 & 4 \\
& $7-8$ & 30.0 & 34 \\
$\mathrm{Cd}$ & $6-8$ & 46.4 & 38 \\
& $6-7$ & 17.0 & 8 \\
& $7-8$ & 15.2 & 5 \\
$\mathrm{Cu}$ & $6-8$ & 29.6 & 13 \\
& $6-7$ & 65.7 & 17 \\
& $7-8$ & 41.2 & 31 \\
$\mathrm{~Pb}$ & $6-8$ & 64.5 & 48 \\
& $6-7$ & 31.6 & 5 \\
& $7-8$ & 21.0 & 30 \\
$\mathrm{Tl}$ & $6-8$ & 46.0 & 35 \\
& $6-7$ & 12.4 & 8 \\
& $7-8$ & 3.3 & 4 \\
& $6-8$ & 15.2 & 12 \\
\hline
\end{tabular}

in Table I, shows that labile complexation with inorganic ligands also occurs. For copper and lead, the largest decrease in $i_{\mathrm{p}}$ occurs between $\mathrm{pH} 6$ and 7 and the largest cathodic shift in $E_{\mathrm{p}}$ occurs between $\mathrm{pH} 7$ and 8 . Since $\Delta i_{\mathrm{p}}$ represents the influence of nonlabile complexation and $\Delta E_{\mathrm{p}}$ represents the combined influence of both labile and nonlabile complexation, then nonlabile complexation of copper and lead is the predominant interaction at the lower $\mathrm{pH}$ values and labile complexation becomes increasingly more important with increasing $\mathrm{pH}$. In the case of cadmium and thallium, both $\Delta i_{\mathrm{p}}$ and $\Delta E_{\mathrm{p}}$ are relatively small. Nonlabile complexation appears to be the predominant interaction for both metals; however, the extent of such complexation appears to decrease with increasing $\mathrm{pH}$ for thallium but is relatively constant for cadmium. The extent of nonlabile complexation is relatively constant for bismuth, but labile interactions appear to increase with increasing $\mathrm{pH}$.

The overall results ( $\mathrm{pH}$ interval 6-8) indicate that copper is the most extensively complexed of the five trace metals. Bismuth and lead undergo approximately equivalent degrees of complexation and cadmium and thallium are the least complexed. The exact nature of these species is unknown. Ernst, Allen \& Mancy (1975) and Bilinski, Huston \& Stumm (1976) have concluded that the carbonate ion would be the most predominant ligand involved in the interactions of copper and lead with a carbonate medium; the hydroxide ion would be relatively unimportant. These same workers have also concluded that cadmium would exist primarily as the hydrated species and should undergo little complexation. Our findings that cadmium undergoes no labile complexation and relatively little nonlabile complexation tends to support these conclusions. The existence of bicarbonate and mixed hydroxo-carbonato trace metal complexes has not been thoroughly investigated; however, such complexes are generally assumed to be unimportant.
The effect of hardness metal ions on the inorganic complexation of trace metals was determined by titrating solutions of $5.0 \times 10^{-8} \mathrm{M}$ trace metal with calcium at $\mathrm{pH} 6,7$, and 8 . The calcium concentration was varied over the range $5.0 \times 10^{-5}$ to $2.2 \times 10^{-3} \mathrm{M}$. Both $i_{\mathrm{p}}$ and $E_{\mathrm{p}}$ were found to be essentially constant over this concentration range; consequently, the data presented in Table 1 are considered representative and are the mean values obtained during the titrations.

If calcium were able to compete successfully with the trace metals, then trace metal complexation would be less extensive in the presence of calcium than in its absence. As a result of this decreased complexation, $E_{\mathrm{p}}$ would have a more anodic value in the presence of calcium than in its absence. Furthermore, if the competition were for nonlabile ligands, $i_{\mathrm{p}}$ would be greater in the presence of calcium than in its absence. Within experimental error $\left( \pm 10 \%\right.$ for $i_{\mathrm{p}}$ and $\pm 3 \%$ for $E_{\mathrm{p}}$ ) values in the presence of calcium are identical to those in its absence; therefore, calcium has no effect on either the labile or the nonlabile inorganic interactions of the five trace metals studied. This lack of successful competition with the trace metals probably results from the fact that calcium forms predominantly ionic salts with the available hydroxo- and carbonato-ligands. Since these salts would be dissociated in the dilute solutions employed. little interaction would take place between calcium and the inorganic ligands. Results of titrations with magnesium were similar to those observed with calcium.

\section{Interactions with organic ligands}

Both inorganic and organic ligands are simultaneously present in the natural environment; consequently, the coordination chemistry of such aquatic systems can be viewed not only as the competition between various cations for available ligands, but also as the competition between inorganic and organic ligands for the available cations. To study these interactions in a carbonate medium, humic acid was chosen as the source of organic ligands because of its natural occurreno in aquatic systems and because of the wide variety of potential complexing sites which such substances present to trace metal ions. The interactions were studied as a function of $\mathrm{pH}$ by observing the ASV characteristics of the trace metals during titrations of $5.0 \times 10^{-8} \mathrm{M}$ trace metal with $0-20 \mu \mathrm{g} \mathrm{ml} l^{-1}$ humic acid and during the titration of $5 \mu \mathrm{g} \mathrm{m}^{-1}$ humic acid with $0-1.4 \times 10^{-7} \mathrm{M}$ trace metal. The effect of calcium was determined by performing these titrations in the absence of calcium as well as in the presence of $1.0 \times 10^{-3} \mathrm{M}$ calcium. The supporting electrolyte was identical to that used to study inorganic interactions; namely, $1.0 \times$ $10^{-3} \mathrm{M} \mathrm{Na}_{2} \mathrm{CO}_{3}$ and $9.0 \times 10^{-3} \mathrm{M} \mathrm{K}_{2} \mathrm{SO}_{4}$.

Figure 1 shows the variation in $i_{\mathrm{p}}$ during titrations of cadmium with humic acid. The decrease in $i_{\mathrm{p}}$. with increasing humic acid concentration indicates the for- 

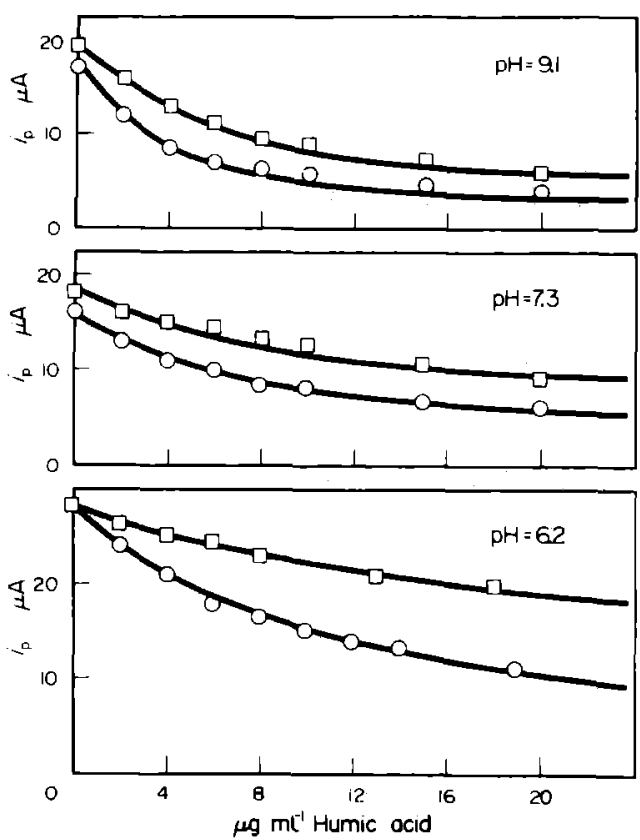

Fig. 1. The effect of calcium and $\mathrm{pH}$ on the variation of $i_{\mathrm{p}}$ during the titration of $5.0 \times 10^{-8} \mathrm{M}$ cadmium with humic acid. $O$ calcium absent; $\square 1.0 \times 10^{-3} \mathrm{M}$ calcium present.

mation of nonlabile cadmium-humic acid complexes. In the absence of calcium the decrease in $i_{p}$ as the humic acid is increased from 0 to $20 \mu \mathrm{g} \mathrm{ml}^{-1}$ amounts to $63.2,65.6$, and $76.5 \%$ at $\mathrm{pH} 6.2,7.2$ and 9.1 , respectively. Thus, nonlabile complexation increases not only with increasing humic acid concentration but also with increasing $\mathbf{p H}$. In the presence of calcium $i_{\mathrm{p}}$ is larger than when calcium is absent; the decrease amounts to only $33.3,50.0$, and $69.2 \%$ at $\mathrm{pH} 6.2,7.2$ and 9.1 , respectively. These percentages suggest that calcium is relatively effective in releasing cadmium from its nonlabile humic acid complexes.

The variation in $E_{\mathrm{p}}$ during the titration of cadmium with humic acid is shown in Fig. 2. $E_{\mathrm{p}}$ becomes more cathodic with increasing humic acid concentration; furthermore, the magnitude of this cathodic shift clearly increases with increasing $\mathrm{pH}$. Although labile complex formation may contribute to this cathodic shift, these results at least confirm the observations made from the $i_{\mathrm{p}}$ results. $E_{\mathrm{p}}$ in the presence of calcium is clearly more anodic than those measured in its absence. This is further evidence that decreased cadmium complexation occurs in the presence of calcium. The anodic shift is clearly more pronounced at $\mathrm{pH} 9.1$ than at the other pH values; however, no such anomaly is found in the $i_{\mathrm{p}}$ results. This would suggest that at this $\mathrm{pH}$ calcium releases cadmium from both labile and nonlabile complexes. In such a case, $i_{\mathrm{p}}$ would only indicate a release from nonlabile complexes and $E_{\mathrm{p}}$ would be indicative of release from both labile and nonlabile.

The titration of humic acid with cadmium appears to be inconsistent with the results obtained during the titration of cadmium with humic acid. Figure 3 shows the variation in $i_{\mathrm{p}}$ during such titrations. The curves are clearly linear and exhibit decreasing slope with increasing $\mathrm{pH}$. This is indicative of labile humic acid complexation superimposed on the nonlabile in organic complexation with the carbonate medium The apparent inconsistency between Figs. 1 and 2 on one hand and Fig. 3 on the other hand has been discussed elsewhere (O'Shea \& Mancy, 1976) and is due to the operational definition of the terms labile and nonlabile; the interactions are of an intermediate type. Nevertheless, Fig. 3 confirms the ability of calcium to release cadmium and subsequently inhibit its complexation with humic acid.

Thallium exhibits behavior somewhat different from that of all the other trace metals studied. The variation in $i_{\mathrm{p}}$ with humic acid concentration is shown in Fig. 4. With the exception of $\mathrm{pH} 9.1$ where there is an $18.2 \%$ decrease, humic acid has no effect on $i_{\mathrm{p}}$. Thus, nonlabile complexation between thallium and humic acid does not occur at $\mathrm{pH} 6.2$ or 7.2. It is not surprising, therefore, that the presence of calcium has no effect on $i_{\mathrm{p}}$. At $\mathrm{pH} 9.1$ some minimal nonlabile complexation does occur; however, the constant $i_{\mathrm{p}}$ in the presence of calcium indicates that calcium competition is successful and these nonlabile thallium-humic acid interactions are completely inhibited.

The $E_{\mathrm{p}}$ results for thallium are shown in Fig. 5 . Since nonlabile complexation at $\mathrm{pH} 6.2$ and 7.2 is nonexistent, the small cathodic shifts in $E_{\mathrm{p}}$ result from labile thallium-humic acid interactions. The cathodic shift is most pronounced at $\mathrm{pH} 9.1$ because both labile and nonlabile interactions occur at higher pH's.
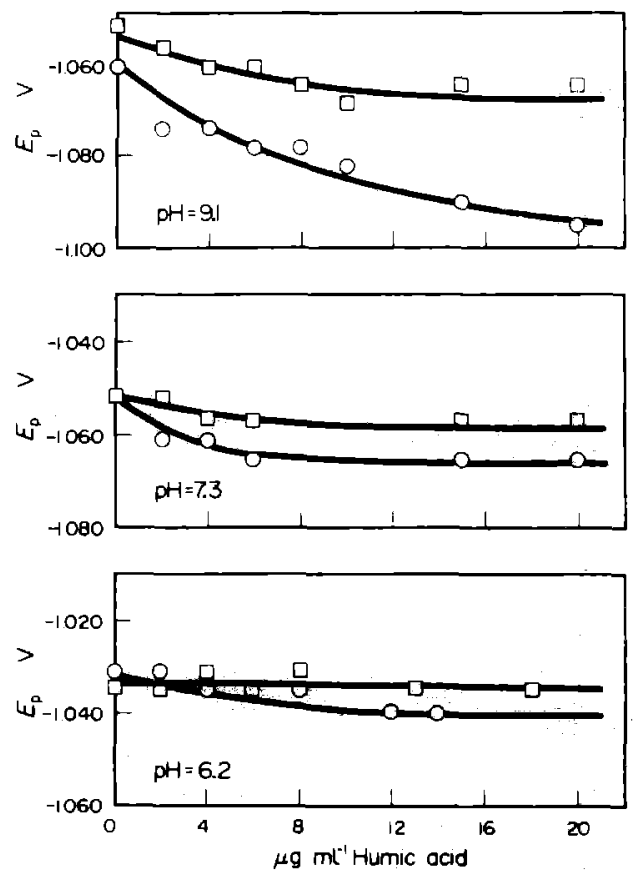

Fig. 2. The effect of calcium and $\mathrm{pH}$ on the variation of $E_{\mathrm{p}}$ during the titration of $5.0 \times 10^{-8} \mathrm{M}$ cadmium with humic acid. $O$ calcium absent; $\square 1.0 \times 10^{-3} \mathrm{M}$ calcium present. 

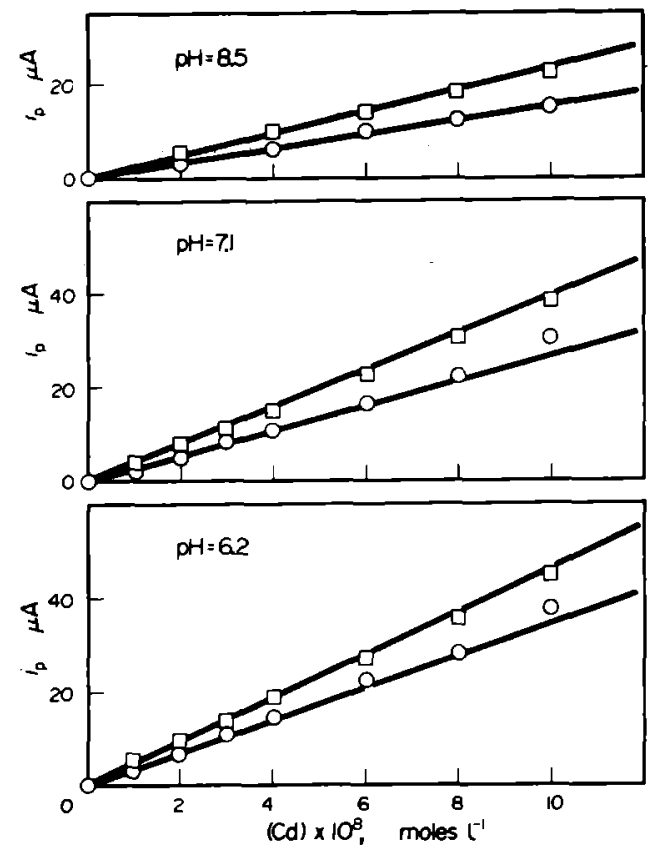

Fig. 3. The effect of calcium and $\mathrm{pH}$ on the variation of $i_{\mathrm{p}}$ during the titration of $5 \mu \mathrm{g} \mathrm{ml}^{-1}$ humic acid with cadmium. O calcium absent; $\square 1.0 \times 10^{-3} \mathrm{M}$ calcium present.

$E_{\mathrm{p}}$ in the presence of calcium is more anodic than in its absence. This shows that calcium successfully competes with thallium for the labile ligand sites. In fact, at $\mathrm{pH} 6.2 E_{\mathrm{p}}$ in the presence of calcium is constant; therefore, since both $i_{\mathrm{p}}$ and $E_{\mathrm{p}}$ are constant in the presence of calcium, thallium complexation does not occur in the presence of calcium.
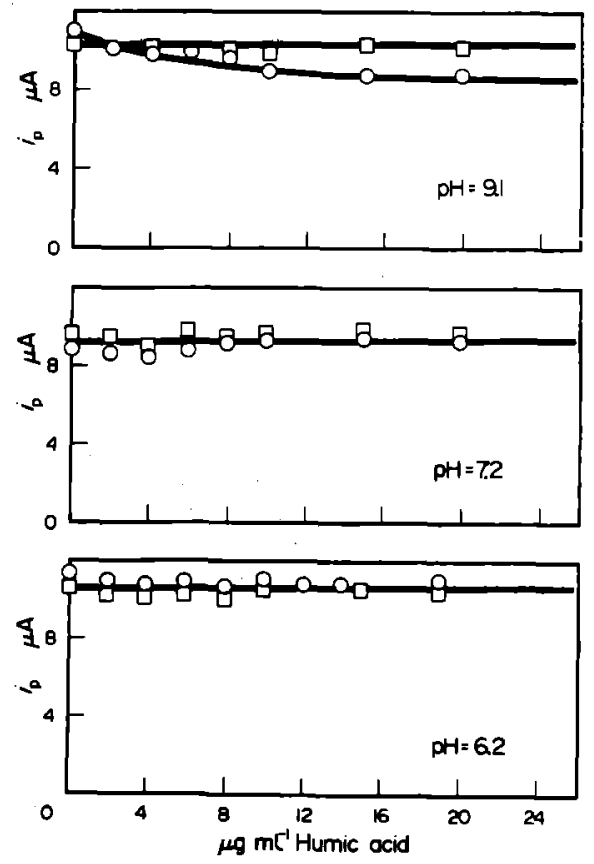

Fig. 4. The effect of calcium and $\mathrm{pH}$ on the variation of $i_{\text {p }}$ during the titration of $5.0 \times 10^{-8} \mathrm{M}$ thallium with humic acid. $O$ calcium absent; $\square 1.0 \times 10^{-3} \mathrm{M}$ calcium present.
The results obtained with thallium are significant not only because of the information which they provide concerning thallium-organic interactions, but also because they illustrate the importance of measuring both $i_{\mathrm{p}}$ and $E_{\mathrm{p}}$ when investigating trace metal complexation by these titrimetric techniques. If only $i_{\mathrm{p}}$ had been measured it would have been assumed that thallium-humic acid interactions are nonexistent; however, $E_{\mathrm{p}}$ measurements clearly indicate that this is not the case. In fact, comparison of both measurements leads to the conclusion that labile interactions occur.

Figure 6 shows the results of titrations of copper with humic acid; very strong and complete nonlabile complexation of copper is indicated. The $i_{\mathrm{p}}$ decreases very rapidly and the signal disappears at humic acid concentrations as low as $4 \mu \mathrm{g} \mathrm{ml}^{-1}$. The presence of calcium in the solution has no observable effect on these nonlabile interactions. The disappearance of a copper signal made it impossible to accurately assess the variation in $E_{\mathrm{p}}$; however, the first addition of humic acid to a solution of copper caused a cathodic shift of approximately $50 \mathrm{mV}$. Calcium had no effect on this shift. This substantiates the fact that copper undergoes extensive complexation and that calcium unsuccessfully competes for the binding sites.

Confirmation of these interactions is provided by titrations of humic acid with copper. Results are shown in Fig. 7. The curves are representative of strong, nonlabile interactions between copper and humic acid. At pH 6.2 no appreciable $i_{\mathrm{p}}$ is observed until $4.0 \times 10^{-8} \mathrm{M}$ copper has been added. This concentration represents that needed to saturate the non-
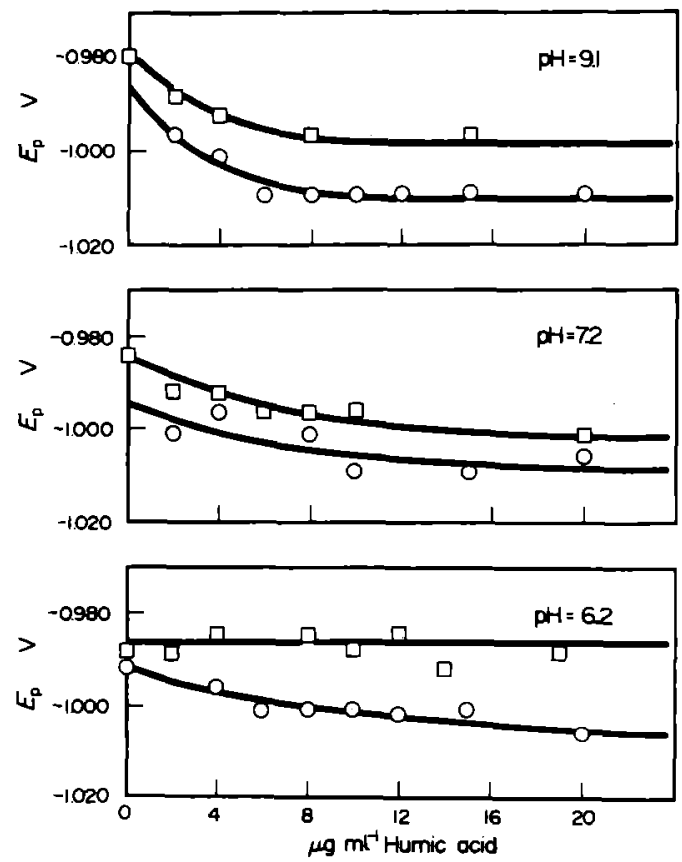

Fig. S. The effect of calcium and $\mathrm{pH}$ on the variation of $E_{\mathrm{p}}$ during the titration of $5.0 \times 10^{-8} \mathrm{M}$ thallium with humic acid. $O$ calcium absent; $\square 1.0 \times 10^{-3} \mathrm{M}$ calcium present. 

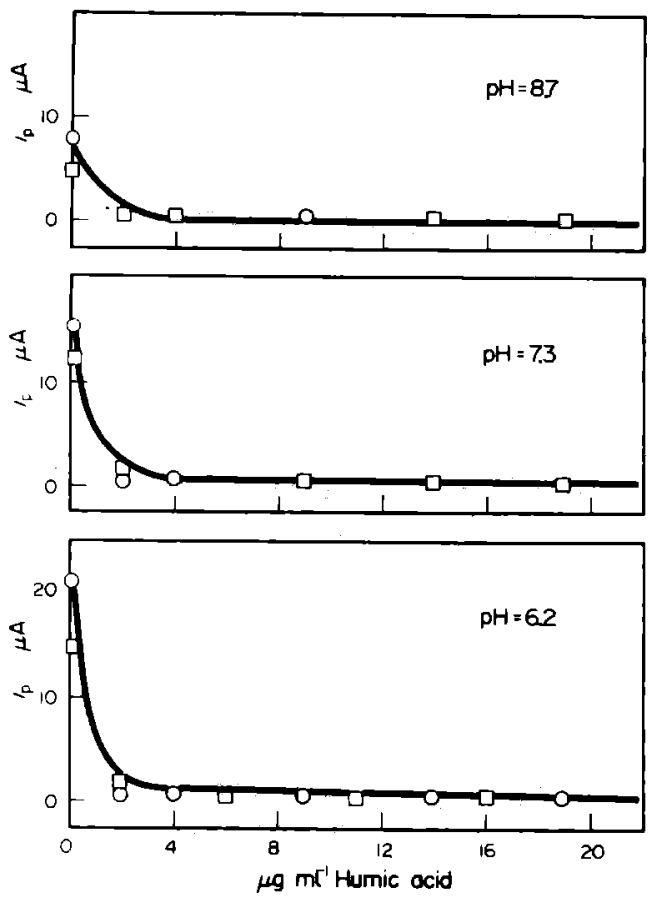

Fig. 6. The effect of calcium and $\mathrm{pH}$ on the variation of $i_{p}$ during the titration of $5.0 \times 10^{-8} \mathrm{M}$ copper with humic acid. $O$ calcium absent : $\square 1.0 \times 10^{-3} \mathrm{M}$ calcium present.

labile ligand sites. At greater concentrations, $i_{\mathrm{p}}$ increases because the additional copper is now being utilized for labile complexation. The extent of nonlabile complexation increases with increasing $\mathrm{pH}$. This is shown by the need for greater copper concentrations in order to obtain a signal; specifically, $8.0 \times 10^{-8} \mathrm{M}$ copper is required at $\mathrm{pH} 7.1$ and $1.0 \times 10^{-7} \mathrm{M}$ is needed at $\mathrm{pH}$ 8.5. The presence of calcium produces no noticeable effect on the non-
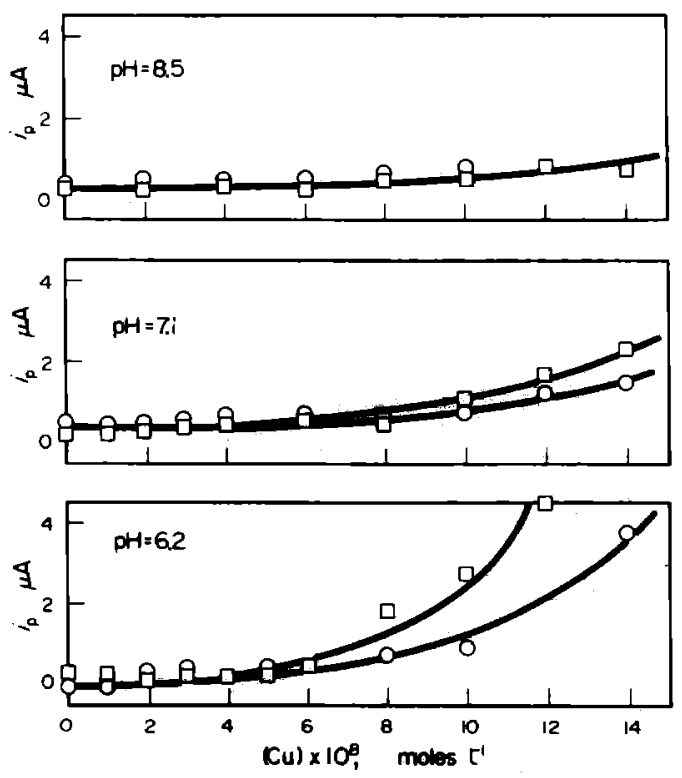

Fig. 7. The effect of calcium and $\mathrm{pH}$ on the variation of $i_{\mathrm{p}}$ during the titration of $5 \mu \mathrm{g} \mathrm{m} \mathrm{m}^{-1}$ humic aeld with copper. $O$ calcium absent; $\square 1.0 \times 10^{-3} \mathrm{M}$ calcium present. labile interactions; however, calcium does appear 10 release some copper from labile fractions at $\mathrm{pH} 6.2$ and 7.1. The small and poorly-defined peaks obtained during these titrations resulted in unreliable $E_{\text {r }}$ measurements.

Bismuth and lead exhibit behavior which is similar to one another but different from that of the other trace metals. The.titration of bismuth with humic acid shown in Fig. 8 is typical of these two trace metals A decrease in $i_{\mathrm{p}}$ with increasing humic acid concentration is observed. As with the other trace metals, this indicates nonlabile interactions. What is unusual is the fact that the extent of these interactions appears to decrease with increasing $\mathrm{pH}$. This decreasing nonlabile complexation is shown by a $100,94.6$ and $64.3 \%$ decrease in $i_{\mathrm{p}}$ at $\mathrm{pH} 6.2,7.5$, and 9.1 , respectively, as the humic acid concentration is varied over the range $0-20 \mu \mathrm{g} \mathrm{ml}^{-1}$. Calcium has no apparent effect on the magnitude of $i_{\mathrm{p}}$ and, therefore, is unable to compete for the nonlabile sites.

The $E_{\mathrm{p}}$ results are shown in Fig. 9. In the absence of calcium the curves show the expected cathodic shift with increasing humic acid concentration. The magnitude of this cathodic shift is independent of $\mathrm{pH}$. This shows that the extent of complexation is constant over the $\mathrm{pH}$ range studied. Since nonlabile complexation decreases with increasing $\mathrm{pH}$, labile complexation must increase with increasing $\mathrm{pH}$. The presence of calcium results in $E_{\mathrm{p}}$ values which are anodic to those obtained in its absence. This effect is small but appears to be more pronounced at $\mathrm{pH} 7.5$ and 9.1 than at 6.2. Since $i_{\mathrm{p}}$ results showed no calcium effect, these results reveal that calcium causes a small inhibition of labile bismuth-humic acid interactions.
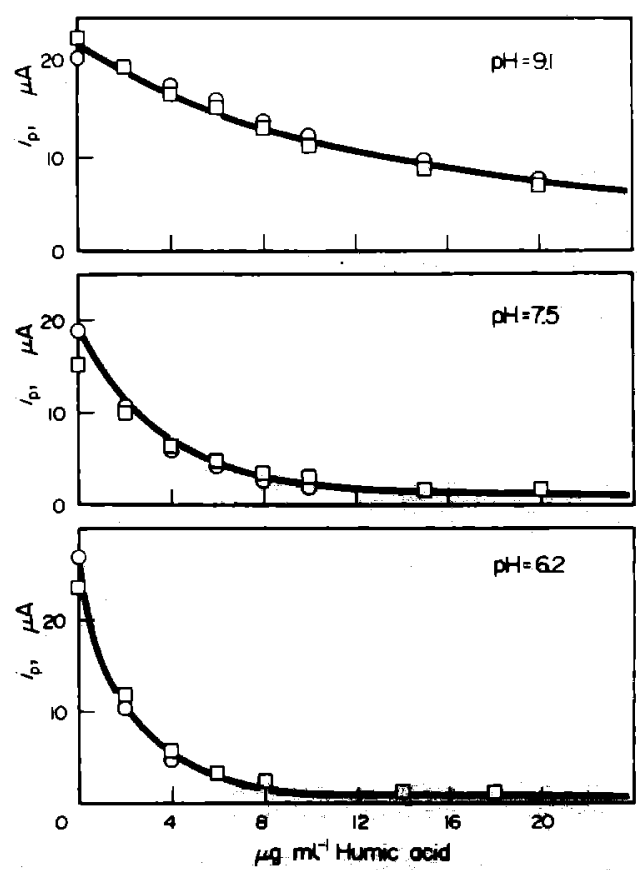

Fic 8. The effect of calcium and pH on the variation of 1. during the titration of $5.0 \times 10^{-1} \mathrm{M}$ bismuth with humic acid. $O$ calcium absent; $\square 1.0 \times 10^{-3} \mathrm{M}$ calcium present. 


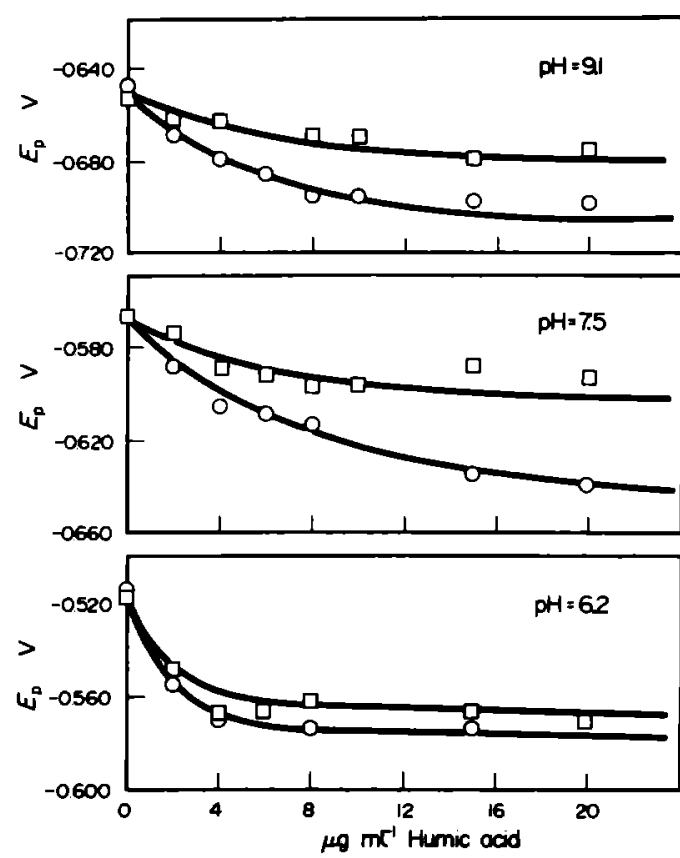

Fig. 9. The effect of calcium and $\mathrm{pH}$ on the variation of $E_{\mathrm{p}}$ during the titration of $5.0 \times 10^{-8} \mathrm{M}$ bismuth with humic acid. $O$ calcium absent; $\square 1.0 \times 10^{-3} \mathrm{M}$ calcium present.

The titration of humic acid with bismuth is shown in Fig 10. An apparent decrease in nonlabile complexation and increase in labile complexation is shown; at $\mathrm{pH} 6.2$ the nonlabile ligands are saturated at $4.0 \times 10^{-8} \mathrm{M}$ bismuth and only $2.0 \times 10^{-8} \mathrm{M}$ bismuth is needed at $\mathrm{pH}$ 7.1. Only labile interactions are indicated at $\mathrm{pH}$ 8.4. The effect of calcium is again observed to be small and involves only the labile interactions. Measurements of $E_{\mathrm{p}}$ during these titrations confirm these conclusions. Lead was found to show very similar behavior.

Analysis of the five trace metal ions in the presence of $5.0 \times 10^{-4} \mathrm{M}$ magnesium indicated that the effect of magnesium is minimal when compared to that of calcium. Although this might be due to the fact that the concentration of magnesium is smaller than that of calcium, the use of higher magnesium concen-
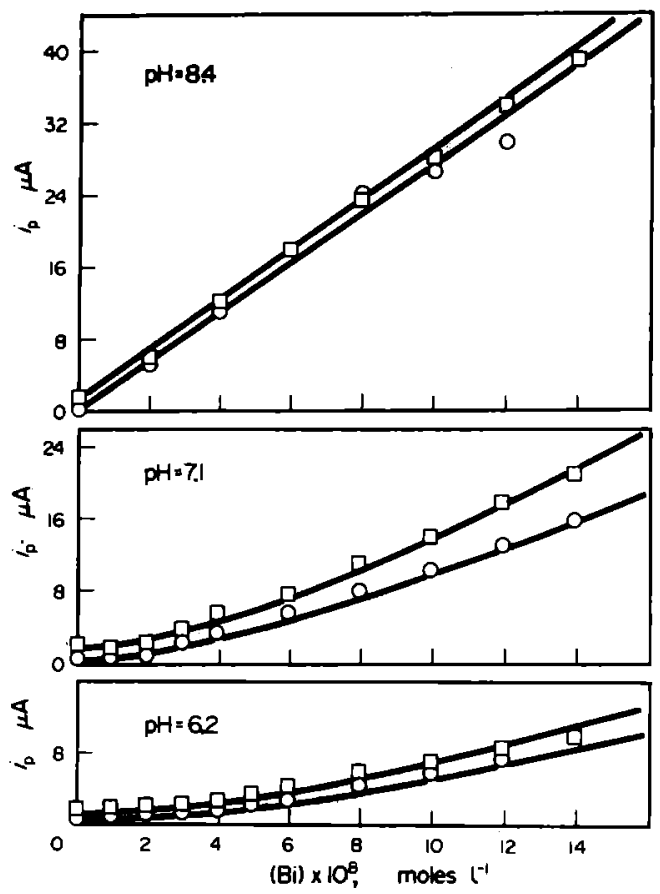

Fig. 10. The effect of calcium and $\mathrm{pH}$ on the variation of $i_{\mathrm{p}}$ during the titration of $5 \mu \mathrm{g} \mathrm{ml}^{-1}$ humic acid with bismuth. $O$ calcium absent; $\square 1.0 \times 10^{-3} \mathrm{M}$ calcium present.

trations would represent a situation not commonly found in natural waters. As a result, it can be concluded that the effect of hardness metal ions on trace metal-orgainic interactions is an effect exerted primarily by the presence of calcium ions.

\section{CONCLUSIONS}

The effect of $\mathrm{pH}$ and calcium on the complexation of trace metals with the hydroxo- and carbonatoligands present in a carbonate medium is summarized in Table 3. Although each metal ion behaves somewhat differently in both the extent and type of interactions which take place, nonlabile complexation appears to be generally more pronounced at $\mathrm{pH}$ values between 6 and 7 and labile interactions appear to become increasingly more important with increas-

Table 3. Summary of the effect of $\mathrm{pH}$ and hardness metal ions on trace metal-inorganic interactions in $1.0 \times 10^{-3} \mathrm{M} \mathrm{Na}{ }_{2} \mathrm{CO}_{3}$ and $9.0 \times 10^{-3} \mathrm{M} \mathrm{K}_{2} \mathrm{SO}_{4}$

\begin{tabular}{lll}
\hline Metal & \multicolumn{1}{c}{$\begin{array}{c}\text { Effect of } \\
\text { increasing } \mathrm{pH}\end{array}$} & $\begin{array}{c}\text { Effect of } \\
\text { hardness metals }\end{array}$ \\
\hline $\mathrm{Bi}$ & $\begin{array}{c}\text { Constant nonlabile interaction; } \\
\text { increasing labile interaction } \\
\text { Constant nonlabile interaction }\end{array}$ & None \\
$\mathrm{Cd}$ & $\begin{array}{c}\text { Extensive but decreasing nonlabile } \\
\text { interactions; increasing labile } \\
\text { interactions }\end{array}$ & None \\
$\mathrm{Cu}$ & $\begin{array}{c}\text { Decreasing nonlabile interaction; } \\
\text { increasing labile interaction }\end{array}$ & None \\
$\mathrm{Pb}$ & Decreasing nonlabile interaction & None \\
$\mathrm{Tl}$ & &
\end{tabular}


Table 4. Summary of the effect of $\mathrm{pH}$ and hardness metal ions on trace metal-humic acid interactions in $1.0 \times 10^{-3} \mathrm{M} \mathrm{Na}_{2} \mathrm{CO}_{3}$ and $9.0 \times 10^{-3} \mathrm{M} \mathrm{K}_{2} \mathrm{SO}_{4}$

\begin{tabular}{lcc}
\hline Metal & $\begin{array}{c}\text { Effect of } \\
\text { increasing } \mathrm{pH}\end{array}$ & $\begin{array}{c}\text { Effect of } \\
\text { hardness metals }\end{array}$ \\
\hline $\mathrm{Bi}$ & $\begin{array}{c}\text { Decreasing nonlabile } \\
\text { interaction; increasing } \\
\text { labile interaction }\end{array}$ & $\begin{array}{c}\text { Small decrease in labile } \\
\text { interaction }\end{array}$ \\
$\mathrm{Cd}$ & $\begin{array}{c}\text { Increasing interaction } \\
\text { of intermediate labile- } \\
\text { nonlabile character }\end{array}$ & $\begin{array}{c}\text { Decrease in extent of } \\
\text { interaction; most pronounced } \\
\text { of all trace metals }\end{array}$ \\
$\mathrm{Cu}$ & $\begin{array}{c}\text { Extensive and increasing } \\
\text { nonlabile interaction }\end{array}$ & $\begin{array}{c}\text { Small decrease in labile } \\
\text { interaction }\end{array}$ \\
$\mathrm{Pb}$ & $\begin{array}{c}\text { Decreasing nonlabile } \\
\text { interaction: increasing } \\
\text { labile interaction }\end{array}$ & $\begin{array}{c}\text { Small decrease in labile } \\
\text { interaction }\end{array}$ \\
$\mathrm{Tl}$ & $\begin{array}{c}\text { Extensive labile inter- } \\
\text { action; small nonlabile } \\
\text { interaction at high } \mathrm{pH}\end{array}$ & $\begin{array}{c}\text { Decrease in labile inter- } \\
\text { action increasing with } \\
\text { decreasing } \mathrm{pH}\end{array}$ \\
\hline
\end{tabular}

ing $\mathrm{pH}$. The need for both $i_{\mathrm{p}}$ and $E_{\mathrm{p}}$ measurements in order to differentiate between nonlabile, labile, and "free" metal ions has been demonstrated. This work has also shown that complexation of trace metals by the inorganic legands commonly found in natural waters is extensive and probably involves all the trace metal ions which may be found in the aquatic system. If the trace metal ions employed in this study can be considered representative of typical metallic ions and oxidation states likely to be encountered in a natural water, then one can conclude from the results that there is no general. relationship between oxidation state and the type or extent of complexation. Even thallium(I), which is widely considered to be a metal ion which undergoes little complexation, has been observed to interact to some degree with the inorganic ligands found in the carbonate medium.

Table 4 summarizes the effect of $\mathrm{pH}$ and calcium on the complexation of trace metals with humic acid in a carbonate medium. The fact that each trace metal exhibits clearly individualistic behavior in its association with organic matter makes generalization diffcult and, perhaps, even misleading. Nonetheless, the association of trace metals with organic matter appears to be far more intense than the trace metalinorganic interactions. As in the case of the inorganic interactions, there appears to be no correlation between the oxidation state of metals and their behavior toward organic matter. Calcium successfully competes with trace metals for labile binding sites and thus releases trace metals from their labile complexes. Calcium is unsuccessful in releasing trace metals from nonlabile complexes. Successful competition by calcium is most pronounced in the case of cadmium; it does not appear to be highly competitive with the other trace metals.

Studies of metal-humic acid systems by Guy \& Chakrabarti (1976) revealed two types of binding sites with a difference in stability constants of approximately 10. If the weaker of these two types of sites is also the more labile, then it is possible that the addition of calcium releases trace metals from these sites by forming stronger complexes with the humic acid. On the other hand, trace metals would form stronger complexes than calcium at the nonlabile sites and, therefore, calcium would be unable to compete. The fact that calcium is associated to a relatively high degree with humic substances at $\mathrm{pH} \geqq 3$ (Benes, Gjessing \& Steinnes, 1976) indicates that when trace metals are introduced to a natural water containing both humic substances and calcium, the metal ions will bind to the nonlabile sites (and might release calcium from these sites) but will be unable to complex with the labile sites. In other words, calcium will inhibit labile interactions between metals and humic acids but will not affect any nonlabile interactions.

These interpretations and conclusions must necessarily be treated as overly simplistic because they are based on complexation phenomena alone and do not take into consideration any competing or interfering phenomena occurring at the electrode surface Consequently, the existence of adsorption on the electrode surface (Brezonik, Brauner \& Stumm, 1976) would certainly alter these interpretations, particularly at low $\mathrm{pH}$, and would introduce a significantly greater degree of complexity into the system. The diagnostic criteria employed above would not be invalidated by the presence of such phenomena; however, their application to trace metal behavior in natural water systems would be rendered more difficult.

Acknowledgement-This work was partially supported by a USPHS Traineeship under Grant No. 5P3-WP-177-03S2.

\section{REFERENCES}

Benes P., Gjessing E. T. \& Steinnes E. (1976) Interactions between humus and trace elements in fresh water. Water Res. 10, 711-716 
Bilinski H., Huston R. \& Stumm W. (1976) Determination of the stability constants of some hydroxo and carbonato complexes of $\mathrm{Pb}(\mathrm{II}), \mathrm{Cu}(\mathrm{II}) . \mathrm{Cd}(\mathrm{II})$ and $\mathrm{Zn}(\mathrm{II})$ in dilute solutions by anodic stripping voltammetry and differential pulse polarography. Analytic. chim. Acta 84. 157-164.

Brezonik P. L., Brauner P. A. \& Stumm W. (1976) Trace metal analysis by anodic stripping voltammetry: effect of sorption by natural and model organic compounds. Water Res. 10, 605-612.

Chau Y. K., Gachter R. \& Lum-Shue-Chan K. (1974) Determination of the apparent complexing capacity of lake waters. J. Fish. Res. Bd Can. 31, 1515-1519.

Chau Y. K. \& Lum-Shue-Chan K. (1974) Determination of labile and strongly bound metals in lake water. Water Res. 8, 383-388.

Ernst R., Allen H. E. \& Mancy K. H. (1975) Characterization of trace metal species and measurement of trace metal stability constants by electrochemical techniques. Water Res. 9. 969-979.

Gardiner J. (1974) The chemistry of cadmium in natural water-I. A study of cadmium complex formation using the cadmium specific-ion electrode. Water Res. 8, 23-30.

Gardiner J. (1976) Complexation of trace metals by ethylenediaminetetraacetic acid (EDTA) in natural waters. Water Res. 10, 507-514.
Guy R. D. \& Chakrabarti C. L. (1976) Studies of metalorganic interactions in model systems pertaining to natural waters. Can. J. Chem. 54, 2600-2611.

Guy R. D., Chakrabarti C. L. \& Schramm L. L. (1975) The application of a simple chemical model of natural waters to metal fixation in particulate matter. Can. $J$. Chem. 53, 661-669.

Lasheen R. M. W. (1974) Factors influencing metal uptake and release by sediments in aquatic environments. Ph.D. Dissertation, University of Michigan, Ann Arbor, Michigan.

Maljkovic D. \& Branica M. (1971) Polarography of seawater-II. Complex formation of cadmium with EDTA. Limnol. Oceanogr. 16, 779-785.

Mancy K. H. (1971) Instrumental Analysis for Water Pollution Control, pp. 231-234. Ann Arbor Science Publishers, Ann Arbor, Michigan.

Mancy K. H. (1973) Trace metal characterization by anodic stripping voltammetry. Progress in Water Technology, Vol. 3, Edited by S. H. Jenkins, pp. 63-72. Pergamon Press, New York.

O'Shea T. A. \& Mancy K. H. (1976) Characterization of trace metal-organic interactions by anodic stripping voltammetry. Analyt. Chem. 48, 1603-1607.

Stumm W. \& Morgan J. J. (1970) Aquatic Chemistry, pp. 283-285. Wiley-Interscience, New York. 